\title{
PENERAPAN APLIKASI PENJUALAN ONLINE BERBASIS CUSTOMER RELATIONSHIP MANAGEMENT (CRM) PADA TOKO SUMBER MULYO DI KABUPATEN KUDUS
}

\author{
Heru Saputro, Danang Mahendra \\ Fakultas Sains dan Teknologi, Universitas Islam Nahdlatul Ulama Jepara \\ herusaputro@unisnu.ac.id,danang@unisnu.ac.id
}

\begin{abstract}
The increasing business competition between buying and selling shops to get customers has caused building shops to compete to provide the best service for their customers. Consumer satisfaction is the key to building long-term relationships between customers and building stores. Sumber Mulyo Shop which is four in Ds. Piji Rt.1 Rw.2 Dawe Kudus is engaged in buying and selling building materials. The customer service system that is currently available at the Sumber Mulyo Shop is still utilizing for the process of buying and selling and service manually, namely when in the store to respond to customer complaints. Therefore, complaints are not confidential to building shops. The registration process is still done by recording documents, in recording documents causing the customer service takes longer if one day is needed. In making the registration data report member marketing will be difficult in managing store data so that in recording member transaction data there will be many errors. The method of applying the system used in this study is the method of System Development Life Cycle (SDLC), Unified Modeling Language (UML), and using a web-based programming language, PHP. This CRM service system makes it easy for customers to register members, provide input in the form of criticism and suggestions, and can provide convenience for Sumber Mulyo Shop owners for web-based data processing. In this study using this system needs analysis through a SWOT analysis.
\end{abstract}

Keywords: CRM, Customers, SDLC, SWOT, Analysis

\begin{abstract}
Abstrak
Semakin meningkatnya persaingan bisnis jual beli antar toko bangunan untuk mendapatkan pelanggan telah menyebabkan toko bangunan berlomba-lomba memberi layanan terbaik bagi pelanggannya. Kepuasan konsumen merupakan kunci utama untuk membangun hubungan dalam jangka panjang antara pelanggan dan toko bangunan. Toko Sumber Mulyo yang bertempat di Ds. Piji Rt.1 Rw.2 Dawe Kudus bergerak di bidang jual beli bahan bangunan. Sistem pelayanan pelanggan yang saat ini telah ada pada Toko Sumber Mulyo masih memanfaatkan untuk proses jual beli serta pelayanan secara manual yaitu saat berada di toko untuk menanggapi keluhan pelanggan. Oleh karena itu, keluhan tidak bersifat rahasia bagi toko bangunan. Proses pendaftaran masih dilakukan dengan pencatatan dokumen, dalam pencatatan dokumen menyebabkan customer service membutuhkan waktu lebih lama jika suatu saat dibutuhkan. Dalam pembuatan laporan data pendaftaran member marketing akan kesuliatan dalam mengelola data toko sehingga dalam pencatatan data transaksi member akan banyak terjadi kesalahan. Metode penerapan sistem yang dipakai dalam penelitian ini adalah dengan metode System Development Life Cycle (SDLC), Unified Modelling Language (UML), dan menggunakan bahasa pemrograman berbasis web yaitu PHP. Sistem CRM pelayanan ini memudahkan pelanggan untuk pendaftaran member, memberikan masukan berupa kritik serta saran, dan dapat memberi kemudahan pemilik Toko Sumber Mulyo untuk pengolahan data berbasis web. Pada penelitian ini menggunakan analisis kebutuhan sistem ini melalui analisis SWOT.
\end{abstract}

Kata kunci: CRM, Pelanggan, SDLC, Analisis, SWOT 


\section{PENDAHULUAN}

Semakin meningkatnya persaingan bisnis antar toko bangunan untuk memperoleh customer sehingga menyebabkan toko bangunan saling bersaing untuk pemberian layanan ke pelanggan yang terbaik. Untuk menjaga keterkaitan pelanggan dengan toko bangunan maka dibutuhkan cara untuk menjaga pelayanan terhadap pelanggan secara positif dengan memenuhi keinginan dari pelanggan. Dibutuhkan sistem Customer Relationship Management (CRM) pelayanan pelanggan dengan membuat aplikasi yang bisa membantu pelanggan dalam memberikan informasi keluhan untuk toko bangunan, dan segala informasi yang terkait dengan pelayanan terhadap pelanggan.

Sistem pelayanan pelanggan yang sudah dilaksanakan sekarang ini pada Toko Sumber Mulyo masih memanfaatkan langkah jual beli serta pelayanan secara manual yaitu saat berada di toko untuk menanggapi beberapa keluhan dari pelanggan sehingga keluhan tidak bersifat rahasia bagi toko bangunan, dalam pendaftaran memberi customer service masih banyak melakukan kesalahan serta butuh waktu yang lumayan lama ketika mencari data member jika dibutuhkan, dalam pengelolaan marketing kesulitan guna pengelolaan data pertemuan dengan toko bangunan ketika akan membuat data pendaftaran member tidak sama dengan transaksi yang sudah terjadi dalam pendaftaran karena masih banyak kesalahan saat melakukan pencatatan member.

Pada permasalahan yang telah dibahas peneliti ingin menerapkan aplikasi penjualan online berbasis Customer Relationship Management (CRM) pada Toko Sumber Mulyo di Kabupaten Kudus. Tujuannya untuk mempermudah customer dan toko bangunan dalam pendaftaran member, pemberian informasi berupa kritik atau saran, mengatur pertemuan antara toko bangunan dengan pelanggan, dan memudahkan pembuatan laporan.

Tujuan dilakukannya penelitian tersebut adalah guna mengetahui proses pelayanan pelanggan yang telah dilakukan sekarang ini pada Toko Sumber Mulyo, menganalisis dan merancang sistem dapat membantu memecahkan dan mengurangi masalah yang dihadapi pada sistem pelayanan data terhadap pelanggan yang sedang berjalan, membantu Toko Sumber Mulyo untuk menjaga dan meningkatkan hubungan baik dengan pelanggan, dengan memanfaatkan web yang sudah diterapkan. Loyalitas dan kepuasan pelanggan pada perusahaan dan mengenal lebih dalam lagi mengenai Customer Relationship Management Pelayanan Pelanggan dan dapat diterapkan pada Toko Sumber Mulyo.

\section{Pengertian Sistem}

Sistem yaitu sebuah prosedur relational guna perancangan rancangan komponen yang saling berhubungan dengan maksud agar bermanfaat sebagai kesatuan usaha untuk mendapatkan tujuan yang diharapkan (Indah, 2013)

\section{Pengertian Customer Relationship Management \\ CRM adalah aplikasi yang bermanfaat bagi} perusahaan untuk memperoleh serta penyimpanan data customer serta telah dilakukan hubungan dua arah. Pada perubahan kebijakan dan prosedur saat ini yang didesain guna peningkatan customer serta sales di semua lini perusahaan (Hidayat, t.t.).

\section{Analisis SWOT}

Analisis SWOT adalah suatu model analisis untuk mengidentifikasi seberapa besar dan kecilnya kelemahan dan kekuatan perusahaan serta seberapa besar dan kecilnya ancaman serta peluang yang kemungkinan dapat terjadi. Perubahan serta bisnis yang penuh kerumitan dan tidak pasti, maka dari itu dalam melakukan analisis terhadapt lingkungan dewan perencana strategis diharuskan lebih jeli serta yang relevan harus dipikirkan kembali (Rethingking), didata kembali (Re-inventing dan ditata kembali (Re-engineering). Kekuatan 3R diatas sedapat mungkin dilakukan dalam menetukan tujuan, sasaran dan strategi, taktik dan kebijakan perusahaan atau organisasi (Fuad, t.t.). 


\section{Bahasa Pemrograman Web}

Bahasa scripts ataupun pemrograman banyak terdengar jenisnya, antara lain yaitu JAVA Scripts, PHP, dan lain sebagainya. Di sistem ini, berbagai aplikasi yang dipakai yaitu PHP, mempertimbangkan bahwa PHP mempunyai banyak kelebihan dibanding bahasa sejenisnya, seperti :

1) Pada sistem operasi dengan server berbeda PHP masih dapat berjalan.

2) Dalam pembuatan PHP mudah pembuatannya serta menjalankannya cepat.

3) Bahasa serve-side yang terpopuler sekarang ini yaitu PHP

4) Di sistem operasi Windows, UNIX, serta Macintosh PHP masih berjalan. (Hidayat, t.t.).

\section{Pengertian SDLC}

SDLC yaitu sebuah langkah pengembangan atau pengubahan software dengan metodologi dan model yang dipakai orang guna pengembangan sistem software sebelumnya. (berdasarkan best practice atau cara-cara yang sudah teruji baik) (Fuad, t.t.).

\subsection{Pengertian XAMPP}

XAMPP yaitu sebuah perangkat lunak yang berguna menjalankan web menggunakan pengolah data MYSQL pada komputer local berbasis PHP. CPanel server virtual bisa dikatakan XAMPP. Yang membantu dalam memodifikasi web dengan model offline atau terkoneksi internet. (Fuad, t.t.).

\subsection{Pengertian PHP MyAdmin}

PHP MyAdmin adalah aplikasi yang berguna untuk membuat database, pengguna (user), memodifikasi tabel, maupun megirim database secara cepat dan mudah tanpa harus menggunakan perintah (Command) SQL (Fuad, t.t.).

\section{METODE PENELITIAN Objek Penelitian}

Penulis melakukan penelitian pada Toko Sumber Mulyo yang berempat di Ds. Piji Rt.1 Rw. 2 Dawe Kudus. Metode pelayanan pelanggan yang diberikan toko tersebut kepada pelanggan agar pelanggan merasakan kepuasan pelayanan yang diberi ke customer. Di sistem yang berjalan untuk mengetahui informasi pelaggan dapat datang langsung atau telepon kepada toko untuk menanyakan informasi produk dan harga yang dibutuhkan kepada Customer Service yang bertugas. Untuk memberikan informasi diskon member dengan langkah memberi informasi ketentuan yang nanti didapatkan dari member tersebut. Toko dapat melakukan kerjasama dengan mendaftarkan pelanggan sebagai member dengan memilih kategori member sama dengan yang dipilih. Pelanggan dapat memberikan masukan berupa saran atau kritik kepada toko tentang pelayanan atau produk yang dijual dengan melalui ulasan website. Pembuatan laporan dokumen untuk diberikan kepada pemimpin atas masukan dari pelanggan berupa saran atau kritik dan pendaftaran member dari pelanggan.

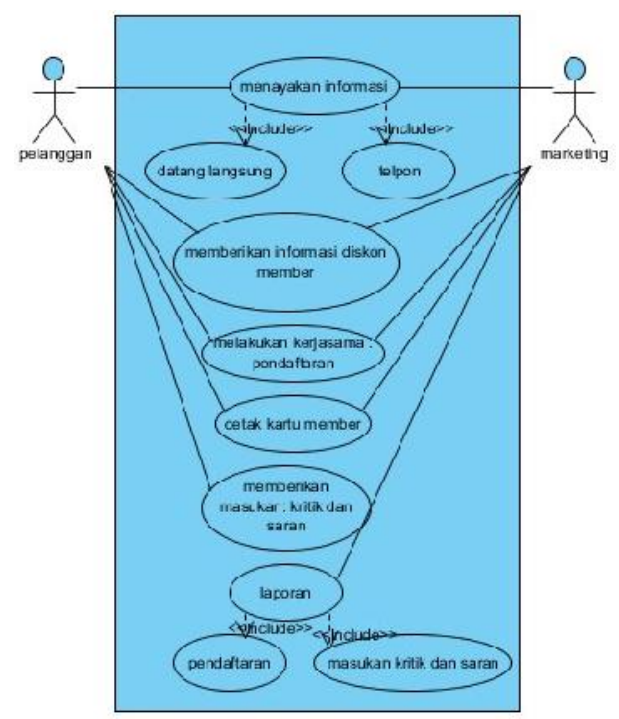

Gambar 1. Use Case Diagram system yang masih berjalan.

Tabel 1. Skenario Use Case Berjalan

\begin{tabular}{|c|lrr|}
\hline Aktor & \multicolumn{3}{|c|}{ Pelanggan, Marketing } \\
\hline Skenario & $\begin{array}{l}\text { Pihak pelanggan } \\
\text { informasi }\end{array}$ & kepada & marketing \\
dengan & datang & langsung \\
& kepada dan telepon, marketing \\
memberikan informasi diskon & kepada pihak pelanggan \\
berdasarkan dengan member, & melakukan & kerjasama, \\
pelanggan & memberikan \\
masukan berupa kritik atau & aran kepada toko seputar \\
saran & layanan yang telah diberikan \\
\hline
\end{tabular}




\section{Desain Penelitian}

Pada penelitian menggunakan pendekatan kuantitatif dengan memakai data sekunder sebagai sumber data utama. Data sekunder yaitu data yang sudah diolah oleh pengumpul data primer yang nantiya disajikan dengan baik ( Wandansari, 2013)

\section{Pengumpulan Data \\ Dokumentasi}

Metode dokumentasi yaitu yang digunakan untuk menelusuri sumber data. Dokumentasi yaitu sebuah informasi yang telah disimpan sebagai bahan dokumentasi. Kebutuhan data dalam dokumentasi ini yaitu bahan informasi yang dikeluarkan sebuah lembaga sebagai contoh buletin, majalah, serta data yang telah terbit berkala (Sucipto, Kusumodestoni, Zyen, \& Husen, 2018).

\section{Penelusuran Data}

\section{a. Data Statistik}

Dalam melakukan penelitian kuantitatif ini peneliti menggunakan analisis data sekunder, serta memanfaatkan analisis data yang ada dipemerintahan dan lainnya.

b. Data Toko

Data yang dipakai berupa data wawancara langsung dan observasi ke Toko Sumber Mulyo

\section{Kuesioner}

Metode kuesioner yaitu berupa rangkaian pernyataan yang ditujukan kepada responden. Berupa daftar pertanyaan kuesioner yang di sebarkan ke responden tentang pengaruh profesional auditor (Arumsari \& Budiartha, 2016). Kuisoner ini disebarkan ke 10 orang. Metode ini dilakukan setelah tahap perancangan aplikasi terselesaikan.

\section{Masalah yang Dihadapi}

Di dalam penelitian yang telah dilaksanakan peneliti dalam sistem yang sedang berjalan, peneliti menemukan beberapa masalah yang ada pada Toko Sumber Mulyo, yaitu :

a) Kurang efektifnya sistem manual yang berjalan saat ini untuk pengisian keluhan pelanggan sehingga setiap pelanggan harus ke toko terlebih dahulu memberikan masukan tentang keluhan.

b) Member masih melakukan pendaftaran dengan melakukan penulisan sebuah dokumen sehingga dapat membuat Customer Service butuh waktu lama dalam melakukan pencarian data member saat dibutuhkan.

c) Marketing kesulitan mengelola data toko ketika akan membuat laporan data pendaftaran member yang tidak sesuai dengan kejadian transaksi pendaftaran karena masih terdapat trouble saat melakukan pencatatan transaksi membernya.

\section{Alternatif Pemecahan Sebuah Masalah}

Setelah melakukan pengamatan dan penelitian dari beberapa masalah yang terdapat pada aplikasi yang sudah dijalnkan saat ini, peneliti mengusulkan beberapa alternatif permasalahan yang dihadapi, antara lain :

a) Dibutuhkan sistem untuk membantu pelanggan melakukan pendaftaran menjadi member.

b) Dibutuhkan sistem mengatur waktu pertemuan untuk membantu pelanggan membuat waktu pertemuan dengan pihak toko.

c) Dibutuhkan sistem untuk mengelola data keluhan pelanggan baik berupa saran atau kritik dari setiap pelanggan.

\section{Pengolahan Awal Data}

Data hasil non particpant observasi diperoleh langsung dari data observasi dengan tahap wawancara ke Dinas Perindustrian dan Perdagangan Kudus.

\section{Metode yang Diusulkan}

Metode yang dipakai dalam mengembangkan aplikasi ini yaitu dengan menggunakan metode analisis SWOT untuk menentukan fitur (CRM) yang diimplementasikan pada sistem marketplace dengan tahapan-tahapan sebagai berikut (Budiardjo \& Irwiensyah, 2008). Analisis SWOT mempunyai tujuan alternatif strategi yang ada diidentifikasi yang merasa sesuai dilaksaakan secara intuitif (Sutrisno, 2011). 


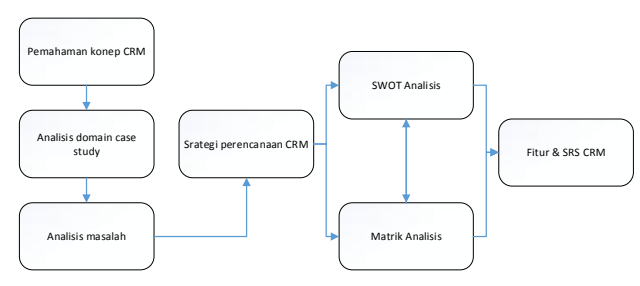

Gambar 2. Kerangka pikir untuk mencari fitur CRM

Dalam fitur CRM mencakup pemahaman kosep CRM, analisis domain case study, analisis masalah, strategi perencanaan CRM, SWOT analisis \& matrik analisis, fitur \& SRS CRM.

1.2.1 Pemahaman konsep CRM

Tahap ini memahami konsep CRM dan framework of dyamic CRM. Tahap ini bertujuan untuk memahami bagaimana membangun konsep CRM dari pemerintah UMKM Kudus dengan tujuan agar UMKM sesuai. Sedangkan framework of dyamic CRM bertujuan untuk pengembangan sistem yang nantinya akan dibangun.

\subsubsection{Analisis domain case study}

Tahap ini peneliti berupaya untuk mendapatkan gambaran umum seputar data guna menjawab penelitian. Peneliti diwajibkan memahami dan membaca data secara lengkap dikarenakan mempunyai tujuan mendapatkan domain.

\subsubsection{Analisis masalah}

Tahap ini meakukan penggalian lebih detail hasil yang diperoleh sebelumnya. Pada langkah ini menganalisa permasalahan pengguna dan menganalisis guna mendapatkan solusi. Tahapannya yaitu menganalisis :

a. Kebutuhan bahan dan alat

b. Kebutuhan fungsionalitas sebuah sistem

c. Kebutuhan non-fungsional sebuah sistem.

1.2.4 Strategi perencanaan CRM

Tahapan ini mempermbangkan situasi secara spesifk yang dihadapi sebuah perusahan, harapan dan kebutuhan customer.

1.2.5 SWOT analisis \& matrik analisis
Tahapan ini mencari informasi dari situasi persoalan internal dan eksternal. Tujuannya untuk menginformasikan kondisi dan gambaran yang menjadi gambaran kelebihan dan kekurangan yang dimiliki guna sebagai pertimbangan nantinya.

1.2.6 Fitur \& SRS CRM

Tahapan ini menjelaskan tentang kerangka kerja yang dipakai guna mendapat fitur \& SRS CRM berdasar framework of dynamic CRM.

\section{HASIL DAN PEMBAHASAN}

Prosedur baru yang akan diusulkan

Pada saat melakukan pengamatan di sistem yang berjalan, maka peneliti menerapkan serta merancang sebuah aplikasi baru dengan tujuan untuk memperbaiki kelemahan pada sistem yang yang telah berjalan saat ini. Dengan dibuatkannya aplikasi penjualan online berbasis customer relationship management pada Toko Sumber Mulyo maka akan memberikan kemudahan terutama pada pelayanan pelanggan. Pelanggan dapat mengakses website Toko Sumber Mulyo, pelanggan dapat melihat informasi pada web CRM seperti menu beranda, product, artikel, tentang kami, cara pembelian, hubungi kami, chat, admin dapat mengelola data product, kategori member, komentar, cara pembelian, pembayaran, cetak laporan.

Untuk pembuatan perangkat lunak, peneliti membuat perancangan aplikasi penjualan online berbasis customer relationship management pada Toko Sumber Mulyo dengan menggunakan sebuah pemrograman PHP.

\section{Diagram Rancangan Sistem}

Rancangan sistem yang akan diusulkan dibuat menggunakan Unified Modeling Language (UML) diagram, sedangkan untuk pembuatan softwarenya dibuat dengan menggunakan database MYSQL serta bahasa pemrograman PHP.

Pada Gambar 3. Use Case diagram yang diusulkan, ada beberapa aktor yang terlibat 
dalam sistem. Di antaranya adalah Pelanggan dan Admin.

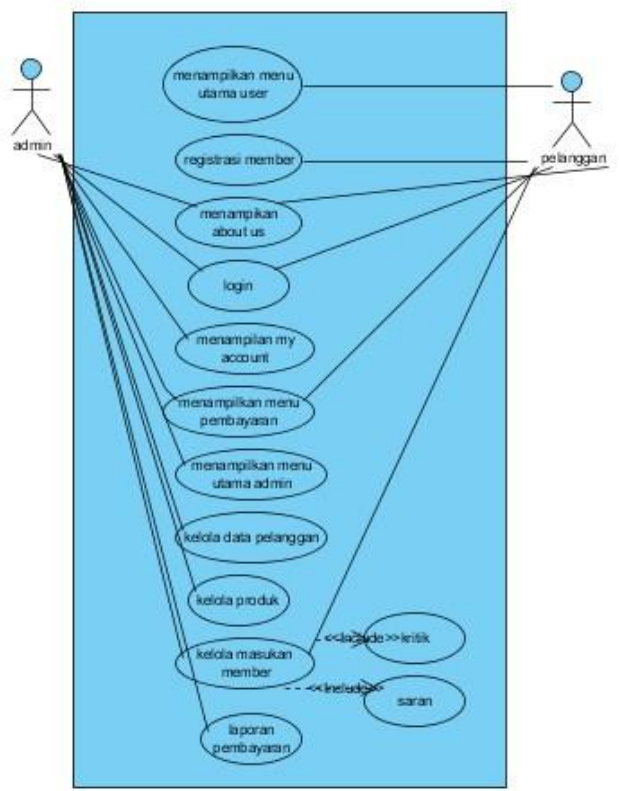

Gambar 3. Use case Diagram yang diusulan

Pada Gambar 3 Use Case Diagram, ada beberapa aktor yang terlibat dalam sistem. Diantaranya adalah Pelanggan, Admin.

Tabel 2. Skenario Use Case diagram yang diusulan

\begin{tabular}{|c|c|c|}
\hline No & Aktor & Deskripsi \\
\hline 1 & Pelanggan & $\begin{array}{l}\text { Aktor dapat mengakses } \\
\text { web CRM untuk login } \\
\text { aktor dapat melakukan } \\
\text { registrasi member, } \\
\text { melihat about us, } \\
\text { merubah my account, } \\
\text { memberikan masukan, } \\
\text { melakukan pembayaran. }\end{array}$ \\
\hline 2 & Admin & $\begin{array}{l}\text { Data pelanggan, produk } \\
\text { penjualan, masukan } \\
\text { member, data laporan } \\
\text { dapat dikelola oleh } \\
\text { Aktor. }\end{array}$ \\
\hline
\end{tabular}

Activity Diagram (diagram aktivitas) adalah diagram yang menggambarkan aliran fungsionalitas dari sistem. Ditahap permodela sistem, diagram aktifitas dapat digunakan untuk menunjukkan aliran kerja sistem. Dapat juga digunakan untuk menggambarkan aliran kejadian.

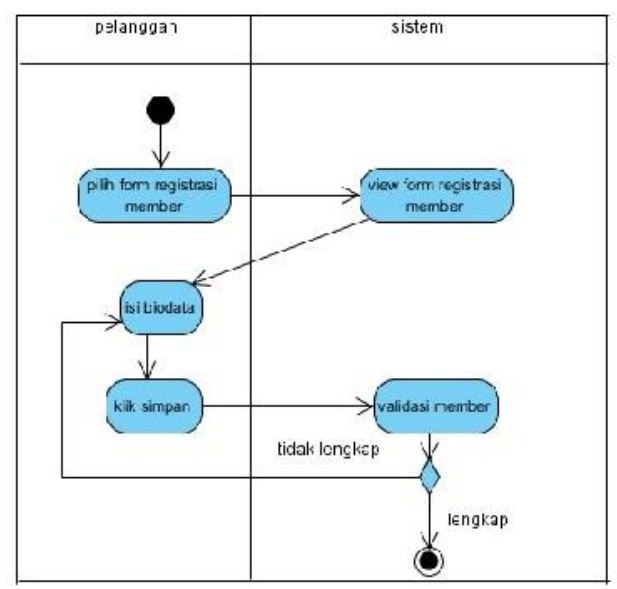

Gambar 4. Diagram activity yang diusulan

Deskripsi Gambar 4 pelanggan melakukan aktifitas registrasi member sebelum masuk ke sistem CRM yaitu dengan mengisi biodata. Apabila data lengkap maka pelanggan telah berhasil daftar. Namun jika data tidak lengkap data tidak akan tersimpan dan akan mendapatkan pesan gagal registrasi.

Di setiap Squence Diagram terdapat aksi aktor yang pertama sekali yaitu terhadap interface. Untuk menggambarkan interaksi antar objek dalam waktu yang berurutan squence diagram digunakan. Pada dasernya Squence Diagram dipakai dalam lapisan abstraksi model objek.

Pada Squence Diagram komponen utamanya terdiri atas objek yang dituliskan dengan kotak segi empat bernama, pesan diwakili oleh garis dengan tanda panah, dan waktu yang ditunjukkan pada proses vertical. Berikut adalah sequence diagram.

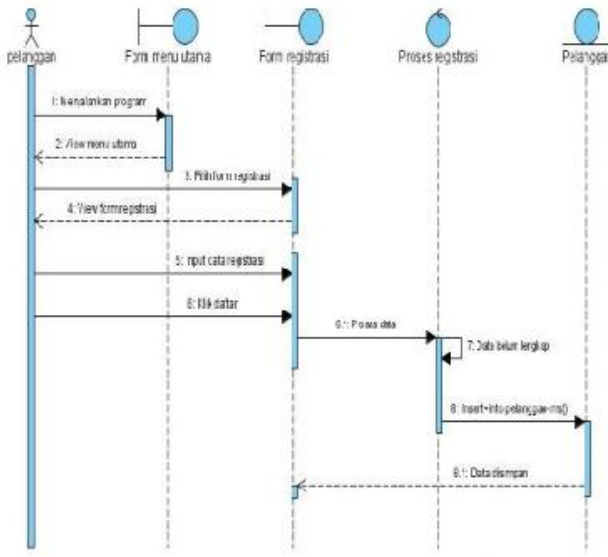

Gambar 5. Sequence Diagram Registrasi Member

Pada Gambar 5 diatas dapat dilihat bahwa ada 4 kelas yang saling berinteraksi, yaitu : 
1. Menu Utama

2. Registrasi

3. Proses Registrasi

4. Simpan Data

Gambar 5 di atas merupakan Sequence Diagram Registrasi Member, proses dimulai dengan menampilkan menu utama. Selanjutnya customer akan menginput biodata didalam sistem. Sistem pun akan memproses data pelanggan yang telah di input setelah itu sistem akan menyimpan data jika data lengkap dan sistem akan menolak dismpan jika data tidak lengkap.

\section{Tampilan Website}

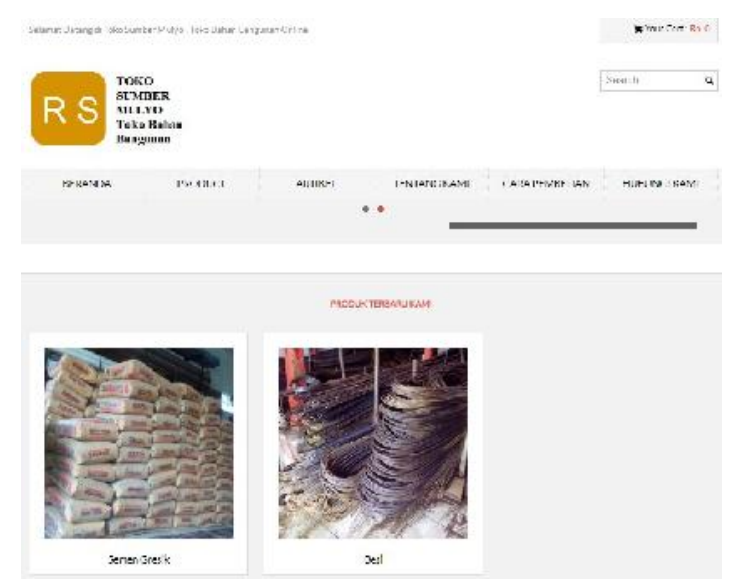

Gambar 6. Tampilan menu utama user

Pada Gambar 6 menampilkan menu beranda, product, artikel, tentang kami, cara pembelian, hubungi kami jika sudah mempunyai akun untuk dapat mengakses masuk ke dalam sistem.

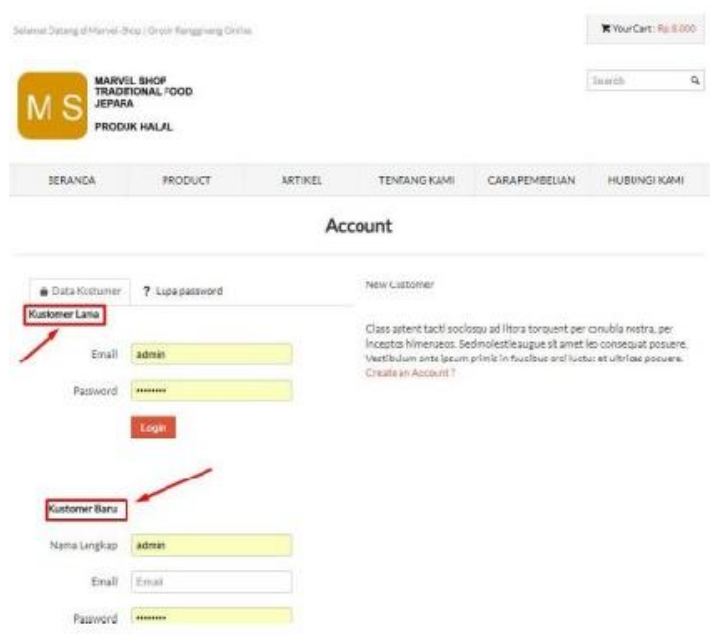

Gambar 7. Registrasi member
Pada Gambar 7 terdapat form registrasi member untuk mengisi biodata pelanggan. jika data sudah terisi lengkap sistem akan menyimpan data, jika data tidak lengkap sistem akan menolak untuk menyimpan data.

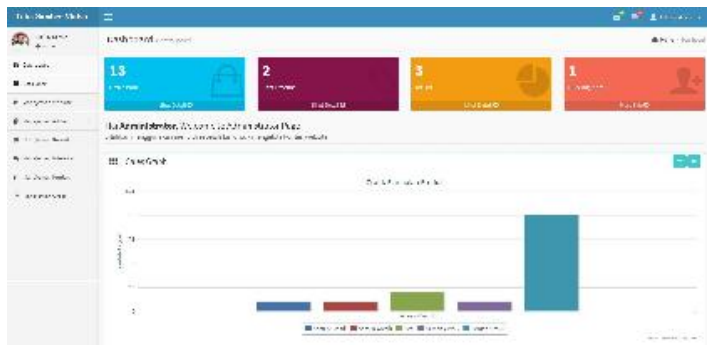

Gambar 8. Halaman Dashboard Admin

Pada Gambar 8 terdapat menu dashboard, data user, manajemen website, manajemen artikel, manajemen produk, manajemen interaksi, manajemen kontak, manajemen order.

\section{Pengujian Black Box}

Pengujian Black Box dibutuhkan untuk menguji fungsionalitas aplikasi agar sesuai harapan. Tabel pengujian black box dapat dilihat di bawah ini.

Tabel 3. Pengujian Black Box

\begin{tabular}{|l|l|l|l|}
\hline No & $\begin{array}{l}\text { Rancangan } \\
\text { Proses }\end{array}$ & \multicolumn{1}{|c|}{ Hasil } & Fungsi \\
\hline 1 & $\begin{array}{l}\text { Login } \\
\text { Admin }\end{array}$ & $\begin{array}{l}\text { Masuk } \\
\text { halaman } \\
\text { admin }\end{array}$ & Sesuai \\
\hline 2 & $\begin{array}{l}\text { Input data } \\
\text { barang }\end{array}$ & $\begin{array}{l}\text { Simpan data } \\
\text { barang }\end{array}$ & Sesuai \\
\hline 3 & $\begin{array}{l}\text { Edit data } \\
\text { barang }\end{array}$ & $\begin{array}{l}\text { Edit data } \\
\text { barang }\end{array}$ & Sesuai \\
\hline 4 & $\begin{array}{l}\text { Hapus data } \\
\text { barang }\end{array}$ & $\begin{array}{l}\text { Hapus data } \\
\text { barang }\end{array}$ & Sesuai \\
\hline 5 & $\begin{array}{l}\text { Laporan } \\
\text { Penjualan }\end{array}$ & $\begin{array}{l}\text { Menampilkan } \\
\text { laporan } \\
\text { penjualan }\end{array}$ & Sesuai \\
\hline 6 & $\begin{array}{l}\text { Komentar } \\
\text { dan saran }\end{array}$ & $\begin{array}{l}\text { Menampilkan } \\
\text { komentar dan } \\
\text { saran }\end{array}$ & Sesuai \\
\hline
\end{tabular}

\section{SIMPULAN}

Berdasarkan penelitian dan pengamatan yang telah dilakukan maka didapatkan beberapa kesimpulan, adalah sebagai berikut:

1. Cara untuk mengatasi sistem data keluhan pelanggan dibutuhkannya sistem yang memberikan masukan berupa kritik 
maupun saran pelanggan secara langsung kepada toko yang sifatnya rahasia, secara sistem dapat diterima langsung perusahaan.

2. Kendalanya masih menggunakan sistem manual, masih dilakukan dengan pencatatan dokumen sehingga membuat customer service membutuhkan waktu yang lama ketika mencari data member jika dibutuhkan, Marketing kesulitan mengelola data toko ketika akan membuat laporan data pendaftaran member yang tidak sesuai dengan kejadian transaksi pendaftaran karena masih terdapat trouble saat melakukan pencatatan transaksi membernya.

3. Untuk dapat membantu marketing mengelola data pelanyanan pelanggan dibutuhkan sistem yang mampu mengelola data pelayanan pelanggan dan dapat memudahkan pelanggan dalam memberikan masukan baik berupa kritik maupun saran. Sistem yang dibuat menggunakan bahasa pemograman PHP dan Database Mysql dengan memberikan hak akses kepada setiap user sesuai dengan kebutuhan user sehingga memudahkan toko dalam mengelola data pelayanan kepada pelanggan.

\section{Saran}

1. Untuk memaksimalkan sistem yang telah dirancang, diperlukan adanya pelatihan kepada karyawan yang terkait atau admin yang akan menggunakan program tersebut agar lebih memahami jalannya sistem

2. Diperlukan penambahan infrastruktur berupa hadware dan software untuk implementasi sistem.

3. Seiring dengan perkembangan jaman dan semakin canggihnya teknologi yang ada, maka aplikasi CRM (Customer Relationship Management) ini dapat dikembangkan lagi di masa yang akan datang dengan berbasis mobile application.

\section{DAFTAR PUSTAKA}

Arumsari, A. L., \& Budiartha, I. K. (2016). Pengaruh Profesionalisme Auditor,
Independensi Auditor, Etika Profesi, Budaya Organisasi, Dan Gaya Kepemimpinan Terhadap Kinerja Auditor Pada Kantor Akuntan Publik Di Bali. 8.

Budiardjo, E. K., \& Irwiensyah, F. (2008). Analisis Fitur Crm Untuk Meningkatkan Kepuasan Pasien - Berbasis Pada Framework Of Dynamic Crm Studi Kasus: Departemen Obstetri Dan Ginekologi FKUI - RSCM Jakarta. 2008(semnasIF), 349-357.

Fuad, H. (t.t.). Perancangan Sistem Infomasi Customer Relationship Management Pelayanan Berbasis Web di PT Sahabat Kreasi Muda. 8(1), 6.

Hidayat, R. (t.t.). Sistem Informasi Ekspedisi Barang Dengan Metode E-CRM Untuk Meningkatkan Pelayanan Pelanggan. $4(2), 5$.

Indah, I. N. (2013). Pembuatan Sistem Informasi Penjualan Pada Toko Sehat Jaya Elektronik Pacitan. 10(2), 5.

Sucipto, A., Kusumodestoni, R. H., Zyen, A. K., \& Husen, M. (2018). Penerapan Aplikasi Mobile Information Karimun Island Menggunakan lonic Framework. 7(1), 10.

Sutrisno, J. (2011). Strategi Pengembangan Teknologi E-Commerce Dengan Metode Swot: Studi Kasus: PT. Chingmix Berhan Sejahtera. 7.

Wandansari, N. D. (2013). Perlakuan Akuntansi Atas Pph Pasal 21 Pada PT. Artha Prima Finance Kotamobagu. 9. 